\title{
Stress cardiomyopathy: clinical features and outcomes
}

\author{
Lilian Hamity ${ }^{1}$, Franco Ramello ${ }^{1}$, Leandro Marani ${ }^{1}$, Alejandro Moyano ${ }^{1}$, Eduardo Moreyra ${ }^{2}$, \\ Luis E. Alday ${ }^{1}$ \\ ${ }^{1}$ Hospital Aeronáutico Córdoba, Córdoba, Argentina; lealday@arnet.com.ar \\ ${ }^{2}$ Professor of Medicine, Universidad Nacional de Córdoba, Córdoba, Argentina
}

Received 6 January 2010; revised 25 January 2010; accepted 29 January 2010.

\begin{abstract}
Objectives: To establish the prevalence, clinical features, and outcomes of the recently recognized stress cardiomyopathy whose physiopathology is still not completely clarified. Material and methods: The prevalence and clinical findings of stress cardiomyopathy were assessed in a group of 378 patients undergoing cinecoronariography for acute coronary syndromes during a 7-year period. The inclusion criteria were severe chest pain, ischemic electrocardiographic changes, reversible left ventricular dyshypokinesia, and normal coronary arteries. Eight patients, 7 female (2.1\% of all patients and $5.0 \%$ of the women), with a mean age of $65.3 \pm$ 8.5 years fulfilled the requirements. Results: The precipitating factor was severe stress in all of them. Cardiac enzymes were slightly raised. There was apical left ventricular dyskinesia in 6 patients, midventricular in another, and diffuse hypokinesia in the remaining. One patient showed moderate mitral regurgitation. The response to conventional treatment and patient outcomes were favorable in all cases with prompt reversal of the left ventricular dyskinesia as assessed by echocardiography. There were 4 recurrences, 2 requiring readmission to hospital, despite continuous treatment with combined alfa and beta adrenergic blockers and calcium antagonists. Conclusions: In our hospital, stress cardiomyopathy had a prevalence of $2.1 \%$ in all patients with acute coronary syndromes and $5.1 \%$ in women and should be considered in their differential diagnosis, especially in middle aged female patients with a history of severe previous stress. There was a favorable outcome but recurrences may occur despite uninterrupted medical treatment following discharge.
\end{abstract}

Keywords: Stress Cardiomyopathy; Takotsubo Syndrome; Myocardial Ischemia; Cardiomyopathy

\section{INTRODUCTION}

The recently described stress cardiomyopathy (SCM), resembles an acute coronary syndrome (ACS) presenting with severe chest pain, left ventricular dys- or hypokinesia not following a determined pattern corresponding to a single involved artery as it occurs in acute myocardial infarction.

It was first described in Japan in the early 90's as "takotsubo syndrome" (from tako: octopus, tsubo: trap) for the similarity with the narrow necked and large rounded bottom fishing pots used in Japan to trap octopus, with the angiographic left ventricular systolic appearance in affected patients [1]. Other names proposed for this syndrome are "apical ballooning syndrome", "broken heart", "transient myocardial stunning", and "transient apical dyskinesia" [2-8]. The syndrome occurs almost exclusively in middle aged women with a clinical onset usually following an episode of severe emotional stress although it may occur during the course of an illness, after some kind of surgery, or even without any provoking factor $[3,9]$. There is a varying severity, with risk of arrhythmias, congestive heart failure, shock and even death. The left ventricular kinetic abnormalities are transient with full recovery of the contractility in about 2 months along with normalization of the electrocardiographic ischemic changes in a variable period of time. The incidence of recurrences has been estimated around $11 \%$ in a group of 100 patients in a 4-year follow-up period [10].

In this study we analyze the features and frequency of SCM in a group of consecutive patients with ACS requiring selective coronarographic study (SCG) during a 7-year period in a general hospital.

\section{METHODS}

We performed a retrospective-prospective, observational study to determine the frequency of SCM, as already defined, in all patients studied by SCG for ACS from March 2002 to February 2009. Inclusion criteria were: a) 
severe, oppressive, chest pain, b) ischemic ECG changes, c) creatin phosphokinase (CPK) enzyme elevation, d) normal or no significant lesions in the coronary arteries, and e) left ventricular dys- or hypokinesia. There were 378 consecutive patients with ACS undergoing SCG, of which 238 (63\%) were males. The mean age was $67.8 \pm$ 9.6 years. Eight patients, 7 of them women, fulfilled the inclusion criteria. Serial laboratory studies, EKG's, and transthoracic color Doppler echocardiograms were performed while admitted at the coronary care unit. They were treated according to current guidelines for the management of ACS's. Following discharge, patients continued tailored medical treatment in keeping with the accompanying risk factors. The left ventricular contractility was assessed by echocardiography. In case of recurrences, patients were studied and treated as in the first admission. The mean follow-up period was $3.8 \pm 2.1$ years. The continuous variables were expressed as mean $\pm \mathrm{SD}$ or median with its range.

\section{RESULTS}

The 8 affected patients made up 2.1\% of all patients with ACS with an incidence for women of $5.0 \%$, while the mean age was $65.3 \pm 8.5$ years. All of them presented to the Emergency Department with severe oppressive chest pain lasting more than 10 minutes. The precipitating factor in all patients was always a severe episode of emotional stress as a result of diverse causes. All patients had electrocardiographic signs of acute ischemia. In 7 of them, there were anterior wall negative $\mathrm{T}$ waves and in only one there was infero-lateral ST segment elevation. (Figure 1) The QTc interval was transiently prolonged in all cases with a median of 475 msec (range 464-490).
The CPK was also mildly elevated in all patients with a median of $290 \mathrm{u} / 100 \mathrm{ml}$ (range 220-390). Echocardiographic studies showed segmental contractile left ventricular parietal abnormalities in 7 cases and generalized hypokinesia in the remaining. SCG was always performed in the acute phase, no longer than 48 hours from the onset of symptoms but for the patient with ST elevation that was initially treated with thrombolysis, and had the study done for recurrence of chest pain on the $5^{\text {th }}$ day after admission. No patient showed significant coronary artery obstructions. Nevertheless, the left ventricular angiographies showed myocardial dys- or hypokinesia with decreased ejection fraction. There was apical dyskinesia in 6 (Figure 2), mid-ventricular involvement in one, associated with mild mitral incompetence, and the last patient had generalized hypokinesia. A summary of all clinical and laboratory findings is shown in Table $\mathbf{1}$.

The median length of stay in hospital was 6 days (range 4 to 10). As already mentioned, treatment was according to the guidelines for ACS's with nitrites, heparin, aspirin, alpha and beta adrenergic blockers agents, vasodilators, and analgesics as required. Following discharge, they were put on adrenergic blockers or calcium antagonists as decided by the personal physician. Besides, they received aspirin, statins, and associated risk factors were addressed (Table 1).

There were 4 recurrences but only 2 required readmission 8 and 18 months following the first episode. All had inadequate control of anxiety disorders. Severe stress was the precipitating factor. The 2 readmitted patients reproduced the initial symptomatology undergoing the same diagnostic and therapeutic measures, again with favorable outcomes. The SCG showed similar findings to the initial study.

Table 1. Clinical and ancillary findings. (AW: anterior wall; BMI: body mass index; ILW: infero-lateral wall; LV: left ventricular; D: dyslipidemia; EF: ejection fraction; SH: systemic hypertension)

\begin{tabular}{|c|c|c|c|c|c|c|c|c|}
\hline Patient & Age & Sex & $\begin{array}{c}\text { Stress trig- } \\
\text { ger }\end{array}$ & $\begin{array}{l}\text { EKG ST \& } \\
\text { T changes }\end{array}$ & QTc (msec) & $\begin{array}{c}\mathrm{CPK}(\mathrm{u} / 100 \\
\mathrm{ml})\end{array}$ & $\begin{array}{l}\text { Associated } \\
\text { risk factors }\end{array}$ & $\begin{array}{l}\text { LV EF \& dys- } \\
\text { function }\end{array}$ \\
\hline A & 46 & Female & $\begin{array}{l}\text { Conjugal } \\
\text { quarrel }\end{array}$ & $\begin{array}{l}\text { Negative T } \\
\text { waves AW }\end{array}$ & 484 & 271 & $\begin{array}{c}\mathrm{BMI}>25 \\
\mathrm{SH}-\mathrm{D}\end{array}$ & 0.36, global \\
\hline B & 49 & Female & $\begin{array}{l}\text { Laboral } \\
\text { stress }\end{array}$ & $\begin{array}{l}\text { ILW ST } \\
\text { elevation }\end{array}$ & 480 & 311 & $\begin{array}{c}\text { BMI > } 25 \\
\text { Diabetes }\end{array}$ & 0.57 , apical \\
\hline $\mathrm{C}$ & 64 & Female & $\begin{array}{c}\text { Family } \\
\text { argument }\end{array}$ & $\begin{array}{c}\text { Negative T } \\
\text { waves AW }\end{array}$ & 478 & 264 & $\begin{array}{c}\mathrm{BMI}>25 \\
\mathrm{SH}-\mathrm{D}\end{array}$ & 0.56, apical \\
\hline D & 62 & Female & Infidelity & $\begin{array}{l}\text { Negative T } \\
\text { waves AW }\end{array}$ & 469 & 220 & $\begin{array}{c}\mathrm{BMI}>25 \\
\mathrm{SH}-\mathrm{D}\end{array}$ & $\begin{array}{c}0.58, \\
\text { mid-ventricular }\end{array}$ \\
\hline $\mathbf{E}$ & 65 & Female & $\begin{array}{l}\text { Spouse's } \\
\text { terminal } \\
\text { illnes }\end{array}$ & $\begin{array}{l}\text { Negative T } \\
\text { waves AW }\end{array}$ & 468 & 253 & SH - D & 0.55, apical \\
\hline $\mathbf{F}$ & 56 & Female & Job loss & $\begin{array}{c}\text { Negative T } \\
\text { waves AW }\end{array}$ & 464 & 276 & Smoking & 0.51, apical \\
\hline G & 59 & Male & $\begin{array}{c}\text { Laboral } \\
\text { problems }\end{array}$ & $\begin{array}{l}\text { Negative T } \\
\text { waves AW }\end{array}$ & 470 & 340 & Smoking & 0.45, apical \\
\hline $\mathbf{H}$ & 73 & Female & $\begin{array}{c}\text { Distressful } \\
\text { disease }\end{array}$ & $\begin{array}{l}\text { Negative T } \\
\text { waves AW }\end{array}$ & 490 & 390 & $\begin{array}{c}\text { SH - D } \\
\text { Smoking }\end{array}$ & 0.50 , apical \\
\hline
\end{tabular}




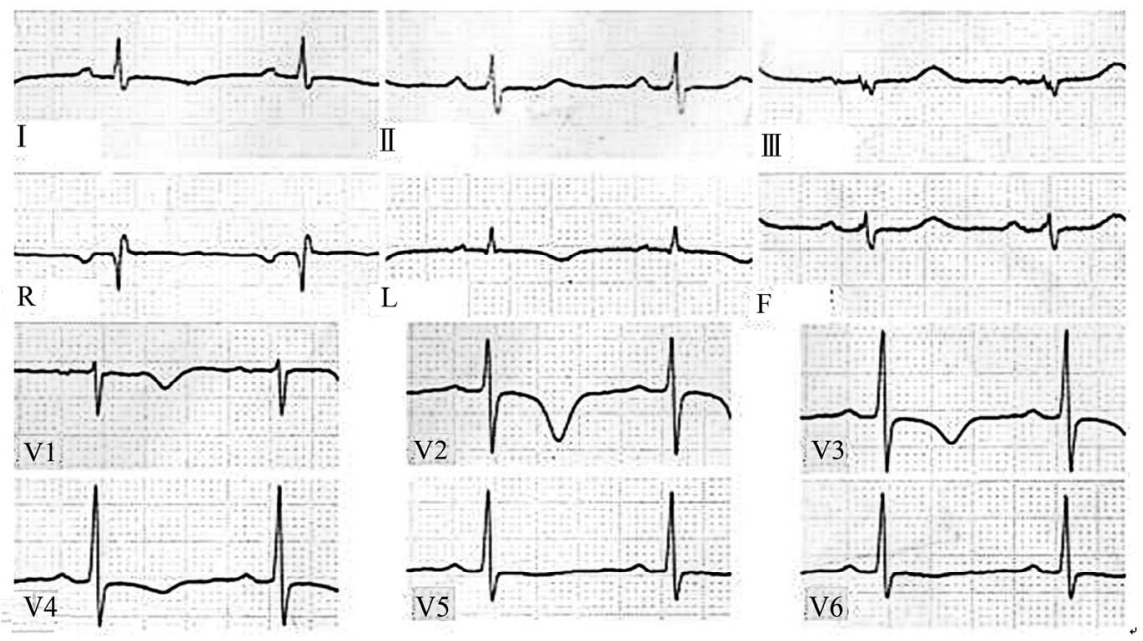

(a) Admission EKG (patient E)

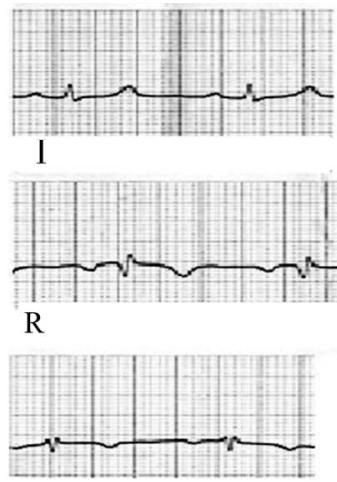

V1

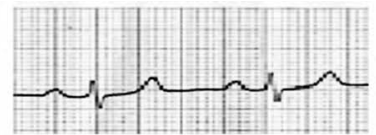

II

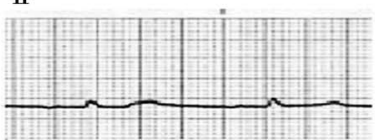

L

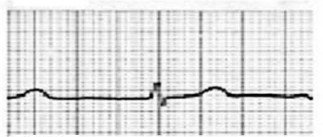

V2

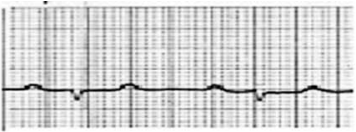

III
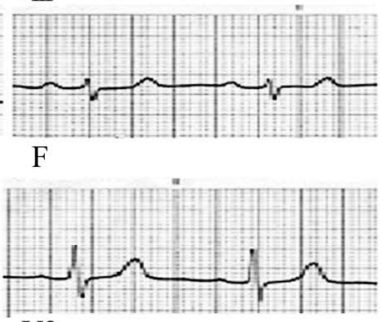

V3

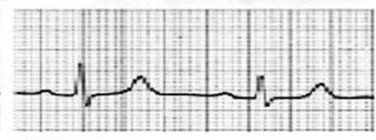

V6

(b) EKG of same patient at discharge

Figure 1. (a) Admission EKG of patient $\mathrm{E}$ showing deeply negative $\mathrm{T}$ waves in the anterior wall and prolonged QT interval; (b) EKG of same patient at discharge with normalization of repolarization abnormalities.
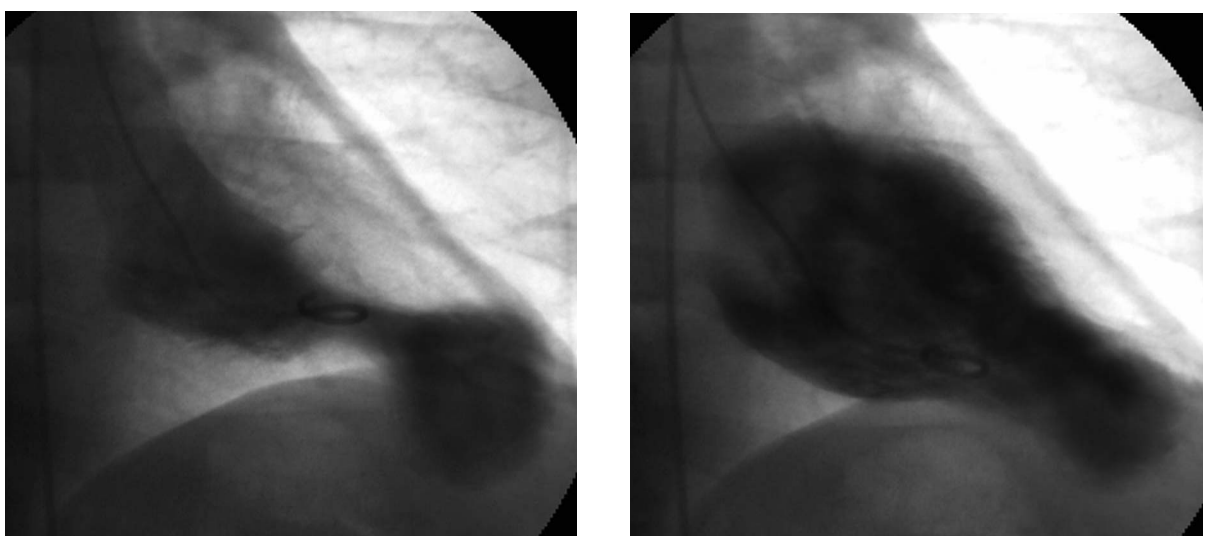

Figure 2. Left ventriculography of patient G in systole and diastole showing typical apical ballooning. 


\section{DISCUSSION}

The findings in our study in patients with SCM mirrored those described in papers following the original description of the syndrome in Japan in the early 90's [1]. The involved population was mainly middle aged females [2]. The chest pain at presentation was indistinguishable from that occurring in ACS and always precipitated by a severe stress episode [9]. The EKG showed acute ischemic changes, usually anterior wall $\mathrm{T}$ wave inversion with lengthening of the QTc interval, accompanied by small rise of the myocardial markers (the CPK enzyme in our study) $[2,10]$. We did not find abnormal Q waves on the EKG though they may also transiently happen [2].

SCG ruled out the presence of significant coronary stenoses while apical left ventricular dyskinesia occurred in 7 patients with extension to the midventricular region in one of them. In the remaining patient there was generalized hypokinesia [12]. One patient also had moderate mitral regurgitation, which with the left ventricular contraction abnormalities were transient [13].

Response to ACS treatment was favorable without major complications resulting in short length of stay. Among them, arrhythmias, heart failure, shock, and very rarely inhospital death have been described [2,9, 12]. Several risk factors were present in all cases and were addressed according to current recommendations. Despite continuous medical treatment following discharge, there were 4 mid-term recurrences, 2 requiring readmission to hospital, with similar course to the initial presentation. Anxiety disorders were more difficult to control in patients with recurrences as compared to those without them. In one study, the frequency of recurrences was around $11 \%$. Patients at risk could not be identified and adrenergic beta blocker therapy did not prevent them [10].

Prevalence of SCM has been estimated in about 2\% of patients presenting with ACS and 3 times higher if just women are considered. We had a somewhat similar occurrence (2.1 and 5.0\%, respectively). According to these figures the diagnosis of SCM should be borne in mind in patients with ACS in any of both situations. $[5,9,14]$. Increased recognition of this syndrome is reflected in the higher number of publications in recent years.

Since the physiopathogenesis of SCM has still not been elucidated several theories have been proposed. There is widespread agreement that an excess of circulating catecholamines would cause the observed derangements through different mechanisms. [4] The occurrence of spasm of the epicardial coronary arteries was initially proposed and then microcirculatory dysfunction. $[1,9]$ However, both were discarded since the dyskinetic territory was more extensive than that corresponding to the perfusion of just one artery and it was not clear whe- ther the microcirculatory dysfunction was the cause or the consequence of SCM. [16] On the contrary, other authors suggested, based on laboratory studies showing higher levels of catecholamines in SCM than in similar control patients with myocardial infarction, a direct myocardial damage. Furthermore, patients undergoing endomyocardial biopsy, showed monocyte inflammatory infiltrates and myocytolysis similar to those occurring in excess catecholamine myocardial damage. [17] More recently, it has been proposed that high level circulating catecholamines would trigger an intracellular signaling pathway that would change the stimulating protein $G$ function to inhibiting protein $\mathrm{G}$ in beta 2 receptors. Although this change would serve as a protecting mechanism against cell apoptosis mediated by intensive activation of beta 1 receptors, it would also produce a negative inotropic effect in cardiomyocytes. The higher apical left ventricular adrenergic receptor density would explain why this region is the most frequently affected in SCM while the basal segments are usually spared. Adrenoreceptor distribution individual phenotypes in SCM patients would explain the different left ventricular regional involvement. [7] Accordingly, less frequent left ventricular hypo-dyskinesias like the midventricular, generalized, and the inverted "takotsubo" affecting basal contractility but sparing the apex might occur $[18,19]$.

On the other hand, in a recent review of all types of SCM, Bybee and Prasad proposed on the basis of experimental studies, that excessive stress would activate the right cortical insula and the ipsilateral cerebral amigdala stimulating the autonomic nervous system, producing a local excess of catecholamines. At their turn, they would activate the calcium channels increasing the cytosolic and mitochondrial calcium levels with release of free radicals and lipid membrane peroxidation., resulting in cell death and band contraction necrosis producing EKG abnormalities and arrhythmias [12].

Some authors, though accepting the role of increased catecholamine secretion as a triggering factor, suggest that SCM would be instead an aborted "myocardial infarction". It is hypothesized that coronary artery lesions, unidentified by SCG because of their very small size, would produce plaque accidents with spontaneous resolution through endogenous fibrinolysis preventing angiographic recognition due to the time elapsed since onset of symptoms and performance of the study. SCM would then be the consequence of previous myocardial ischemia. Radioisotope studies using metabolic markers have shown altered fatty acid handling and glycose transportation probably caused by catecholamine excess and calcium intracellular overload resulting in "myocardial metabolic stunning" [20-22].

The cause of the more frequent occurrence of SCM in menopausic women has not been elucidated. A gender difference has been suggested or else, microcirculatory 
endothelial dysfunction facilitated by a decrease of estrogenic stimulation [5].

Dynamic left ventricular outflow tract obstruction has also been described in SCM patients. [23] It is still not clear if the gradient is the cause or a consequence of the syndrome [16].

Finally, Akashi et al., based on experimental studies in rats, propose that sudden, unexpected, stress, would activate autonomic nervous system neurons with estrogenic receptors causing higher release of catecholamines that would stimulate vascular and cardiac adrenoreceptors resulting in systemic hypertension and increased inotropism. The aforementioned higher expression of apical adrenoreceptors, would be responsible of the dyskinesia at that level through the toxic effect on the cardiomyocytes. The dynamic left ventricular outflow tract obstruction present in some patients with SCM would be caused by the basal myocardial hypercontractility. The loss of estrogenic protection in the nervous system and myocardium following menopause would exaggerate all these disarrangements [15].

The previous discussion shows that the origin and facilitating triggering factors of SCM are still under debate. Since SCM description and better identification are recent, it is still not clear which is the ideal treatment for these patients in the acute phase and after discharge to prevent recurrences. Nevertheless, supported by laboratory animal experimental studies, Akashi et al., recommend combined alfa and beta adrenergic blockers instead of individual administration. Calcium channel antagonists and nitrites would also be effective [15].

\section{CONCLUSIONS}

The prevalence of SCM in a 7-year period in our hospital was $2.1 \%$ of all patients with ACS requiring SCG and $5.0 \%$ if just women were considered. There was an initial favorable outcome with satisfactory response to conventional medical treatment though recurrences occurred in patients with inadequate control in anxiety disorders and 2 of them required readmission to hospital.

\section{REFERENCES}

[1] Dote, K., Sato, H., Tateishi, H., Uchida, T. and Ishihara, M. (1991) Myocardial stunning due to simultaneous multivessel coronary spasms: A review of 5 cases. Journal of Cardiology, 21, 203-214.

[2] Abe, Y. and Kondo, M. (2003) Apical ballooning of the left ventricle: A distinct entity? Heart, 89, 974-976.

[3] Bybee, K.A., Kara, T., Prasad, A., Lerman, A., Barsness, G.W., Wright, S., et al. (2004) Systematic review: Transient left ventricular apical ballooning: A syndrome that mimics ST-segment elevation myocardial infarction. Annals of Internal Medicine, 141, 858-865.

[4] Brandspiegel, H.Z., Marinchak, R.A., Rials, S.J. and Kowey, P.R. (1998) A broken heart. Circulation, 98,
1349.

[5] Pavin, D., Le Breton, H. and Daubert, C. (1997) Human stress cardiomyopathy mimicking acute myocardial syndrome. Heart, 78, 509-511.

[6] Sharkey, S.W., Lesser, J.R., Zenovich, A.G., Maron, M.S., Lindberg, J., Longe, T.F., et al. (2005) Acute and reverseble cardiomyopathy provoked by stress in women from the United States. Circulation, 111, 472-479.

[7] Lyon, A.R., Rees, P.S.C., Prasad, S., Poole-Wilson, P.A. and Harding, S.E. (2008) Stress (Takotsubo) cardiomyopathy-a novel pathophysiological hypothesis to explain cathecolamine-induced myocardial stunning. $\mathrm{Na}$ ture Clinical Practice Cardiovascular Medicine, 5, 22-29.

[8] Juri, J.E., Smith, F.J., Bahamonde, L.A., De Rosa, A. And Salzberg, S. (2005) Discinesia apical transitoria. Rev Argent Cardiol, 73, 64-67.

[9] Gianni, M., Dentali, F., Grandi, A.M., Sumner, G., Hiralal, R. and Lonn, E. (2006) Apical ballooning syndrome or Takotsubo cardiomyopathy: A systematic review. European Heart Journal, 27, 1523-1529.

[10] Elesber, A.A., Prasad, A., Lennon, R.J., Wright, R.S., Lerman, A. and Rihal, C.S. (2007) Four-year recurrence rate and prognosis of the apical ballooning syndrome. Journal of the American College of Cardiology, 50, 448-452.

[11] Tsuchihashi, K., Ueshima, K., Uchida, T., Oh-mura, N., Kimura, K., Owa, M., et al. (2001) Transient left ventricular apical ballooning without coronary artery stenosis: A novel heart syndrome mimicking acute myocardial infarction. Journal of the American College of Cardiology, 38, 11-18.

[12] Bybee, K.A. and Prasad, A. (2008) Stress-related cardiomyopathy syndromes. Circulation, 118, 397-409.

[13] Parodi, G., Del Pace, S., Salvadori, C., Carrabba, N., Olivotto, I. and Gensini, G.F. (2007) Tuscani registry of Tako-Tsubo cardiomyopathy: Left ventricular apical ballooning syndrome as a novel cause of acute mitral regurgitation. Journal of the American College of Cardiology, 50, 647-649.

[14] Elian, D., Osherou, A., Matetzky, S., Hod, H., Guetta, V., Feinberg, M.S., et al. (2006) Left ventricular apical ballooning syndrome: Not an uncommon variant of acute myocardial infarction in women. Clinical Cardiology, 29, 9-13.

[15] Akashi, Y.J., Goldstein, D.S., Barbaro, G. and Ueyama, T. (2008) Takotsubo cardiomyopathy: A new form of acute reversible heart failure. Circulation, 118, 2754-2762.

[16] Nef, H.M., Mollmann, H. and Elsasser, A. (2007) Takotsubo cardiomyopathy (apical ballooning). Heart, 93, 1309-1315.

[17] Wittstein, I.S., Thiemann, D.R., Lima, J.A.C., Baughman, K.L., Shulman, S.P., Gerstenblith, G., et al. (2005) Neurohumoral features of myocardial stunning due to sudden emotional stress. The New England Journal of Medicine, 352, 539-548.

[18] Hurst, R.T., Askew, J.W., Reuss, C.S., Lee, R.W., Swenney, J.P., Fortuin, F.D., et al. (2006) Transient midventricular ballooning: A new variant. Journal of the American College of Cardiology, 48, 579-583

[19] Sanchez-Recalde, A., Costero, O., Oliver, J.M., Iborra, C., Ruiz, E. and Sobrino, J.A. (2006) Pheochromocytomarelated cardiomyopathy inverted takotsubo contractile pattern. Circulation, 113, e738-e739.

[20] Khallafi, H., Chacko, V., Varveralis, N. and Elmi, F. (2008) "Broken heart syndrome”: Catecholamine surge 
or aborted myocardial infarction? The Journal of Invasive Cardiology, 20, e9-e13

[21] Kurisu, S., Inohue, I., Kawagoe, T., Ishihara, M., Shimatani, I., Nishioka, K., et al. (2003) Myocardial perfusion and fatty acid metabolism in patients with tako-tsubo-like left ventricular dysfunction. Journal of the American College of Cardiology, 41, 743-748.

[22] Bybee, K.A., Murphy, J., Wright, R.S., Prasad, A., Rihal,
C.S. and Chareontaitawee, P. (2006) Acute impairment of regional myocardial glucose utilization in the apical ballooning (Takotsubo) syndrome. Journal of Nuclear Cardiology, 13(2), 244-250.

[23] Villareal, R.P., Achari, A., Wilansky, S. and Wilson, J.M.l. (2001) Anteroapical stunning and left ventricular outflow tract obstruction. Mayo Clinic Proceeding, 76, 79-83. 